\title{
Ethical implications of emotional and psychologic ties on human-robot interaction (HRI)-mediated
} learning

\begin{abstract}
This mini-script describes the need to expand knowledge in this regard and improve the potential of future applications derived from the use of humanoids as educational assistants with children. Understanding the importance of highlighting the ethic reflection in this disciplinary field, The text seeks to strengthen and encourage other researchers to join in the construction of an international research program that contributes to the ethical challenges involved in the development of HRI To this end, an updated reflection on post humanities, philosophy of science and technology among other trans disciplinary topics is made to propose an ethical framework in these practices and scientific advances of robotics.
\end{abstract}

Keywords: ethics and robotics, human-robot interaction (HRI), post humanities
Volume 5 Issue 4 - 2019

\author{
Edgar Giovanni Rodriguez Cuberos \\ Faculty of Education, Humanities and Arts Sciences, Juan de \\ Castellanos University Foundation, Colombia
}

Correspondence: Edgar Giovanni Rodriguez Cuberos, Faculty of Education, Humanities and Arts Sciences, Juan de Castellanos University Foundation, Tunja, Colombia.

Email rodriguez.edga26@gmail.com

Received: August 01, 2019 | Published: August 26, 2019

\section{Introduction}

The progressive development of the human-robot interaction (HRI) and the inclusion of Robots in different aspects of the live generate positive impacts on learning. However, the ethical implications derived from social interactions and the construction of affective and psychological bonds have not been studied in depth yet. The development and advancement of new robotic technologies, of artificial intelligence and, in particular, of the production of humanoids oriented to functions of accompaniment, entertainment or education, ${ }^{1}$ suggests the emergence of a new type of human subjectivity. The interaction with these new technologies is unprecedented and their anthropological and ethical implications are little studied so far. While it is true that there are large and dizzying technical advances in this field, ${ }^{1-5}$ reflective processes about what these advances imply for the human condition require greater attention. It is not only a matter of proposing a naive dystopian or utopian vision, but of constructing a field of trans disciplinary studies and researchD ${ }^{6-8}$ involving mechanisms of epistemological surveillance, ethical criticism and political effects as a sphere of human action that favors complementarily between technological developments and applications in everyday life and medical and psychological effects (Figure 1).

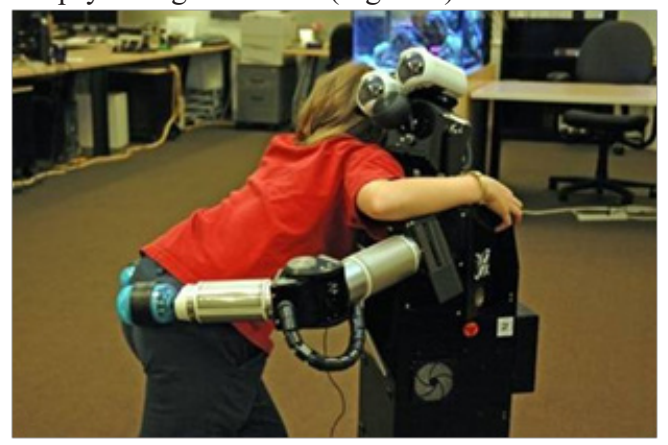

Figure I Embrace between a child and "Robovie", image of the work carried out by the University of Washington and the Telecommunications Research Institute, in which in addition to the technical advance of the prototype, the interaction between children and this type of machines is emphasized. The researchers highlight that the interaction leads children to develop feelings towards the robot and moral attributes, leaving the question open both for the benefits and for the associated risks in terms of social and emotional development. (Source: https://phys.org/news/2012-04-children-humanoidrobot-emotional-moral.html.).
For the time being, this article draws attention to the topic and proposes to scientists, sociologists and humanists at the global level, to commit themselves for the definition of topics, objects and questions of research, in the context of the derivation of HRI technology., Therefore, take advantage of the capacity of the philosophy of science and studies on ethics to understand a phenomenon with immediate impact above our present and future reality. ${ }^{2,6}$

In a very short time, humanoids could be common artifacts in daily life and therefore, their interaction with us will demarcate new forms of subjectivity production. This is what I have called in the field of post humanities: "Trans human settlers". ${ }^{7}$ The trans human settlers are people who will normalize the human- robot relationship and interaction as part of their life experience. This life experience would conform social environments in which machines would be subordinated to human consciousness (at least in appearance). They will be settlers within a new worldview paradigm of a shared world between embodied artificial intelligence and ours (physical and, until now, mortal). ${ }^{6}$

\section{Methodology}

An analytical review of previous investigations ${ }^{1-3}$ have already shown that in general children are quite receptive to interaction with humanoids, but this must be considered within a broader scenario than that shown in the laboratory phase and experimentation with interactions and controlled cycles. Very likely the introduction of robotic technology in market (see for example the rate of consumption of devices such as AIBO or NAO) would exceed the ethical warning instance on emotional implications of its users.

Children in particular may be generating emotional and affective dependencies that would necessarily determine their vision, perspective and position in this new world, in which their companions and tutors may be artifacts with artificial intelligence and humanoid characteristics, pets that enliven their moments of leisure and solitude with the guarantee of not dying.

Interestingly, the way to approach these ethical dilemmas has emerged from the so-called predictive science (formerly known as Science Fiction). Predictive science proposes scenarios where the line that demarcates reality and fiction is very close as we move forward in the developments and applications technologies without adequate anthropological reflection. 
For now, we assume that the applications of the HRI are or tend to be neutral, but we forget the current socio cultural conditions that in fact promote the isolation of people, to dehumanization and absence of emotional criteria that hinders fair, balanced, sustainable and respectful actions. Instrumentalization and alienation are risks that must be detected in the advancement of robotics and its consequences for life on the planet. For this reason, a human learning mediated by machines is not neutral and underlies a form of power and knowledge unprecedented in the history of humanity.

It is necessary to base a field of ethical and philosophical studies that help us to understand the anthropology that underlies the advance of robotic technology and artificial intelligence in applications that involve HRI. ${ }^{7}$ This field of studies must be interdisciplinary and ease communication between researchers of the pure and applied sciences with those of the human sciences to commit in more complex analysis in which could be possible to notice implications that affect the mechanisms of production of human subjectivity in said contexts.

Also, it is required to recover and use philosophical perspectives of high complexity in the reflection about the condition of the contemporary subject, education mediated by new robotic technologies and the ethics and aesthetics of the new century to understand the current phenomenon and generate interdisciplinary dialogues. In this sense, the philosophies of the untimely, the intensity and the immanence will be of great help. The previous is important in order to understand the deep phenomenon of the HRI, although it will be required go further than behavioral algorithms and positive ethologies. The implication of human phenomena such as contradiction, hesitation, uncertainty and oscillation -as referents and principles of human emotion- and their effect on these new anthropological visions will be decisive. ${ }^{5,9}$

\section{Conclusion}

From this brief article, I invite researchers to create a network that addresses these perspectives and contributes to the definition of this ambitious and interesting field of studies which promise the development of an integrating perspective of the sciences. What new emotional dependencies underlie its use? Which affections and emotional ties are the most common? What determines the construction of affective ties in human-robots interaction (HRI)? Which new social and community values could appear? What effect do these technologies have on processes of alienation and social isolation? These and other important questions need to be broadened in the landscape of trans disciplinary studies that help emerging technologies in artificial intelligence and HRI to strengthen the codes of ethics and the limits that, by common agreement of scientists, guarantee epistemic, technical and ethical surveillance of such developments. Although it is true, many of these technologies are already being applied and apparently do not pose any apparent risk, if there are different visions that warn of unprecedented adverse consequences. ${ }^{10}$ Promoting research that explores the psychological implications derived from interactions in human beings is therefore relevant as we are talking about other types of relationships and social interactions. ${ }^{11}$

\section{Acknowledgments}

None.

\section{Conflicts of interest}

The author declares there are no conflicts of interest.

\section{Funding}

None.

\section{References}

1. Belpaeme T, Kennedy J, Ramachandran A, et al. Social robots for education: A review. Science Robotics. 2018;3(21):5954.

2. Benítez Es. Robot human interaction and its educational applications. Thesis national autonomous university, Mexico; 2012.

3. Castro J. Robots could be future playmates for kids. Live Science. 2012.

4. Riek LD, Howard D. Code of ethics for the human-robot interaction profession. In We Robot. 2014.

5. McElroy M. Children perceive humanoid robot as emotional, moral being. 2012.

6. Rodríguez, EG. The immanence of "Puppet Master": towards posthuman social studies. Nomads. 2017;47:123-135.

7. Rodríguez EG. The "other" childhoods that come: notes for an ethic of singularity and subjectivity from children-humanoid interactions. Conference Present and future international congress of the humanities; 2017 Sep 27-30; Bogotá: Colombia; 2017.

8. Rodríguez EG. Performative social science: scopes of a methodological alternative. Nomads. 2008;29:142-155.

9. https://conference.pixel-online.net/NPSE/acceptedabstracts scheda. php?id_abs=2751

10. Deleuze G. Subjectivation Foucault course. Philosophy Papers Reviews. 2016;35(1):221-224

11. https://www.dw.com/es/para\%C3\%ADso-o-robocalipsis/a-49556154 